\title{
In vivo assessment of diaphragm contraction by ultrasound in normal subjects
}

\author{
J Ueki, P F De Bruin, N B Pride
}

\begin{abstract}
Background - Ultrasound allows observation of the thickness of the diaphragm in the zone of apposition in vivo during relaxation and maximum inspiratory efforts.

Methods - Changes of diaphragm thickness were studied by $B$ mode (two dimensional) ultrasound in 13 healthy men aged 29-54 years in the seated position. A high resolution $7 \cdot 5 \mathrm{MHz}$ ultrasound transducer was held perpendicular to the chest wall in the line of a right intercostal space between the anteroaxillary and midaxillary lines to observe the diaphragm in the zone of apposition $0.5-2 \mathrm{~cm}$ below the costophrenic angle. The changes of thickness were observed while breath holding at total lung capacity (TLC), functional residual capacity (FRC), and residual volume (RV). At FRC the thickness while relaxing against a closed mouthpiece and during a maximum inspiratory mouth pressure (PImax) manoeuvre was recorded. The thickening ratio (TR) was calculated as $\mathbf{T R}=$ thickness during PImax manoeuvre/thickness while relaxing.
\end{abstract}

Results - Mean (SD) thickness was 4.5 $(0.9) \mathrm{mm}$ at TLC, $1.7(0.2) \mathrm{mm}$ at FRC, and $1.6(0.2) \mathrm{mm}$ at RV. During the PImax manoeuvre at FRC mean thickness increased from $1.7(0.2) \mathrm{mm}$ during relaxation to $4.4(1.4) \mathrm{mm}$, while mean PImax and TR were -104 (33) $\mathrm{cm} \mathrm{H}_{2} \mathrm{O}$ and $2.6(0 \cdot 7)$, respectively. There was a high degree of correlation between $T R$ and the pressure achieved during the maximum inspiratory manoeuvre $(r=-0 \cdot 82)$.

Conclusions - Ultrasound provides a noninvasive assessment of diaphragm thickness with change of lung volume and during the PImax manoeuvre which should prove useful in assessing diaphragm mass and contraction in respiratory and muscle disease.

(Thorax 1995;50:1157-1161)

Keywords: diaphragm thickness, maximum inspiratory pressure, lung volume.

Accurate quantification of respiratory muscle strength is important in assessing patients with respiratory muscle dysfunction. The simplest method of assessing respiratory muscle strength is by measuring mouth pressure during maximum inspiratory effort (PImax) against a closed airway. ${ }^{12} \mathrm{~A}$ wide range of normal values has been reported. ${ }^{3}$ A similar wide range of values for maximum voluntary force of the quadriceps femoris muscle has been described, ${ }^{4-6}$ but much of this variation is explained by differences in muscle mass as assessed by computed tomographic scanning ${ }^{5}$ or ultrasound. ${ }^{6}$ Ultrasound has been used to a limited extent to evaluate diaphragm thickness non-invasively in the zone of apposition during tidal breathing and with changes in lung volume. ${ }^{78}$ In the present study we have evaluated the role of high resolution $B$ mode (two dimensional) ultrasound in assessing changes in diaphragm thickness, particularly during the PImax manoeuvre at functional residual capacity (FRC) in normal men. The long term objective was to investigate the value of this non-invasive technique in assessing the diaphragm in disease.

\section{Methods}

Thirteen normal men of mean age 37 years (range 29-54), height $175 \cdot 7(5 \cdot 1) \mathrm{cm}, 103 \cdot 1$ $(10.4) \%$ of ideal body weight participated in the study. None of the subjects had any history of cardiopulmonary or neuromuscular disease.

A high resolution $7.5 \mathrm{MHz}$ ultrasound linear probe (PLE 705S Toshiba Medical System Co, Tokyo, Japan) was used to observe the diaphragm in the zone of apposition. Real-time movement of the diaphragm was recorded on B mode (two dimensional) ultrasonography. The ultrasound transducer was placed in the line of a right intercostal space between the anteroaxillary and midaxillary lines in order to observe part of the zone of apposition of the diaphragm $0 \cdot 5-2 \mathrm{~cm}$ below the costophrenic sinus. The inferior border of the costophrenic sinus was easily identified by the level of lung artifact caused by the ultrasound reflected by the air in the lung. The diaphragm was outlined by the two clear bright parallel lines of the pleural and peritoneal membranes (fig 1). ${ }^{78}$ A high resolution ultrasound probe reveals a discontinuous less bright line in the muscular layer which has been shown to be due to connective tissue and vessels running between the muscle fibres. ${ }^{8}$ The transducer was held perpendicular to the chest wall. When the angle of the transducer was changed significantly from perpendicular to the diaphragm, the two parallel lines of the pleura and peritoneum were either distorted or lost altogether. ${ }^{7}$ On B mode pictures the diaphragm thickness was measured from the middle of the pleural line to the middle of the peritoneal line (fig 1). The shortest distance that could be resolved between two lines using this system was $0.3 \mathrm{~mm}$, considerably less than the thickness of the normal relaxed diaphragm. On each \\ Medicine (Respiratory \\ School, Hammersmith \\ Lospital, 12 0NN, \\ J Ueki \\ P F De Bruin
N B Pride




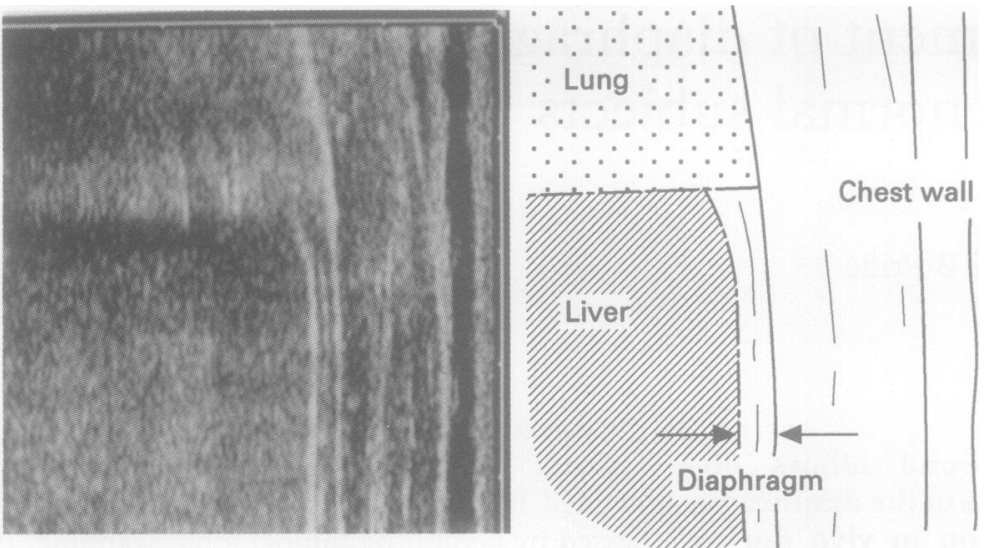

Figure 1 Ultrasonographic view of the normal diaphragm in the zone of apposition (between two arrows) through an intercostal space in a man aged 29 years. Scale division on $x$ and $y$ axes of the photograph is $10 \mathrm{~mm}$.

ultrasound image, measurements of the diaphragm thickness were made to the nearest $0.1 \mathrm{~mm}$ at three points along the zone of apposition; the mean value was used.

In the sitting position the subject was asked to breathe through a conventional flanged mouthpiece which was fitted to a common airway incorporating a Fleisch pneumotachograph and a three-way tap. Changes in lung volume were obtained by integrating the output of the pneumotachograph. The diaphragm thickness was measured by ultrasound while breath holding at total lung capacity (TLC), FRC, and residual volume (RV) with an open airway. Three ultrasound images were obtained and the mean values taken. The subject was then asked to relax at FRC against a closed mouthpiece and then to perform the Pimax manoeuvre by sustaining a maximum inspiratory effort for 1-2 seconds. ${ }^{12}$ The diaphragm was observed simultaneously by ultrasound. The pressure was recorded at the mouthpiece using a variable inductance differential pressure transducer (HP 267B) with small internal volume and linear response over the range of +150 to $-150 \mathrm{~cm} \mathrm{H}_{2} \mathrm{O}$. The occluded mouthpiece had a small leak to ensure glottal patency and to avoid the use of cheek muscles. The Pimax procedure was repeated until no further decreases in pressure were observed and at least three apparently technically satisfactory attempts were obtained. The results presented are the diaphragm thickness in the ultrasound image obtained during the PImax manoeuvre which generated the most negative mouth pressure. The change in diaphragm thickness during the PImax manoeuvre was calculated as the thickening ratio (TR).

$\mathrm{TR}=\frac{\text { Thickness during PImax manoeuvre at FRC }}{\text { Mean thickness while relaxing at FRC }}$

Forced expiratory volume in one second $\left(F V_{1}\right)$ and vital capacity (VC) were measured with a dry bellows spirometer, TLC by body plethysmography, and RV obtained as TLC -VC. The results were compared with standard reference values. ${ }^{9}$

All subjects gave written informed consent to the protocol which was approved by the Hammersmith Hospital research ethics committee.

\section{DATA ANALYSIS}

All values were expressed as mean (SD). The diaphragm thickness at TLC, FRC, and RV was compared by using ANOVA. The thickness while relaxing against a closed airway, while breath holding with open airway, while relaxing against a closed airway, and during the PImax manoeuvre was compared by Student's $t$ test. Correlations between PImax and diaphragm thickness during the various manoeuvres were measured by regression analysis. The relation between thickness during the Pimax manoeuvre and at TLC was tested by correlation analysis. A p value less than 0.05 was taken to be significant. ${ }^{10}$

\section{Results}

STATIC AND DYNAMIC LUNG VOLUMES

Mean (SD) values of $\mathrm{FEV}_{1} 3.9(0.5) 1,98(9) \%$ predicted, VC $4.7(0.6) 1,98(9) \%$ predicted, and RV/TLC 28 (4)\%, 100 (10)\% predicted were all normal.

DIAPHRAGM THICKNESS DURING BREATH HOLDING WITH OPEN AIRWAY (fig 2)

No differences in diaphragm thickness were found along the zone of apposition. Diaphragm thickness at FRC while breath holding with an open airway $(1.7(0.2) \mathrm{mm})$ was identical to the thickness while relaxing against a closed mouthpiece. In six men measurements of relaxed diaphragm thickness were repeated on a

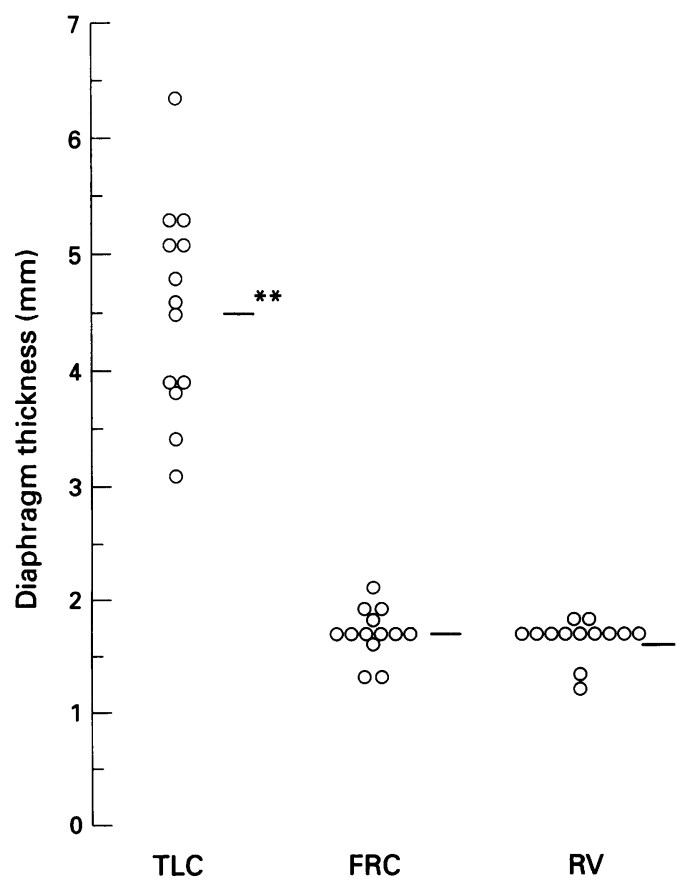

Figure 2 Diaphragm thickness in the zone of apposition while breath holding with open airway at total lung capacity (TLC), functional residual capacity (FRC), and residual volume (RV). Horizontal bars show mean values. ${ }^{* *} p<0.01$ compared with thickness at FRC and $R V$. 


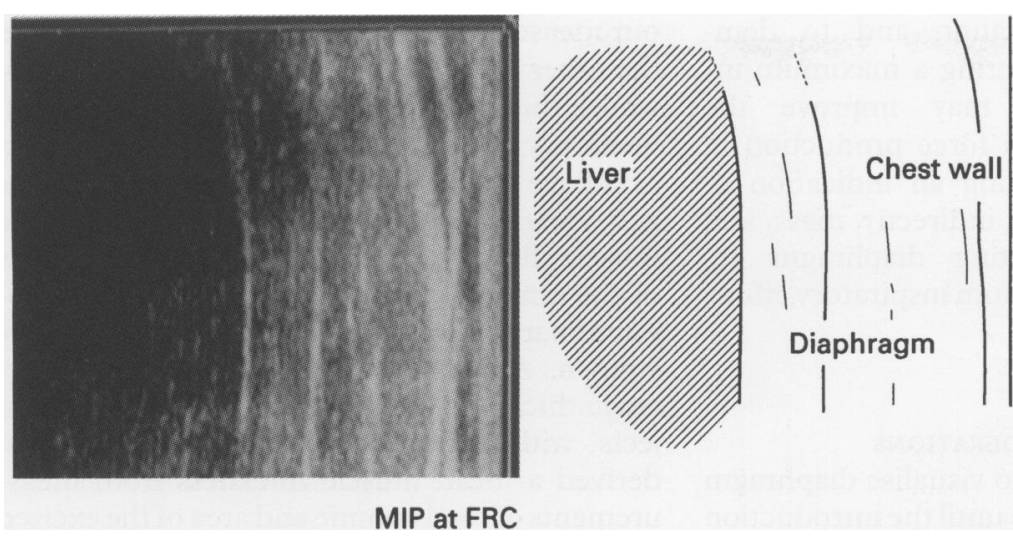

Figure 3 Ultrasonography of the diaphragm contraction in the zone of apposition during PImax manoeuvre in one subject aged 33 years.

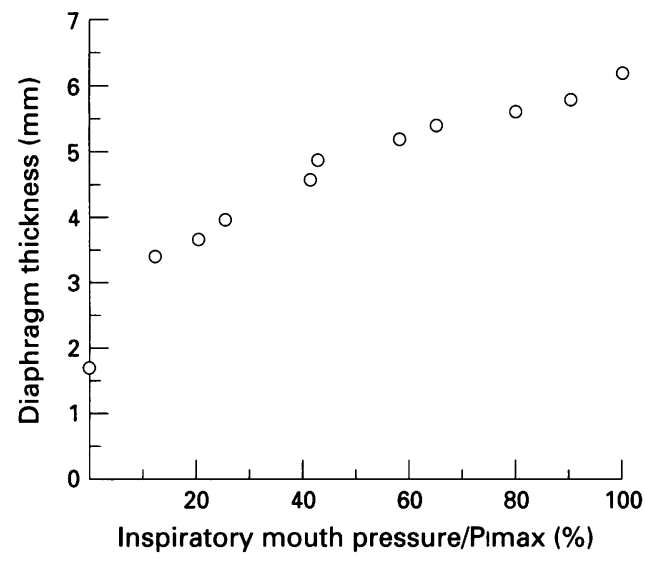

Figure 4 Increase in diaphragm thickness with increasing static inspiratory effort (expressed as \% PImax which was $-138 \mathrm{~cm} \mathrm{H} \mathrm{H}_{2} \mathrm{O}$ ) in the man whose ultrasonogram is shown in fig 3. Note the large increase in thickness between relaxation (0\%) and $10 \%$ inspiratory effort.

second day; in three subjects the mean thickness was identical and the remaining three showed a $0 \cdot 1 \mathrm{~mm}$ difference between the two measurements. A zone of apposition was present in all subjects at TLC. There was a considerable increase in diaphragm thickness when breath holding at TLC with an open airway (and hence contracting the diaphragm); mean (SD) thickness was $4.5(0.9) \mathrm{mm}$, significantly different from values at FRC $(1 \cdot 7(0.2) \mathrm{mm})$ and $\mathrm{RV}(1.6(0.2) \mathrm{mm})(\mathrm{ANOVA}, \mathrm{p}<0.01)$. In 11 men the thickness at TLC was compared when breath holding with an open airway $(4 \cdot 4$ $(0.9) \mathrm{mm})$ and when relaxed against a closed airway $(3.6(0.7) \mathrm{mm})$; thickness was reduced during relaxation in each subject $(p<0 \cdot 01)$.

\section{DIAPHRAGM THICKNESS DURING INSPIRATORY EFFORTS AT FRC}

Although adjustment of probe alignment was sometimes required, diaphragm thickness could be measured during a Pimax manoeuvre (fig 3 ) in all subjects. The increase in diaphragm thickness with increasing inspiratory effort (expressed as \% of PImax) in one man is shown in fig 4. The increase in thickness was alinear and particularly large between relaxation and $10 \%$ of Pimax. A similar relationship was found in a second man studied in an identical fashion. Increased thickness of the diaphragm during

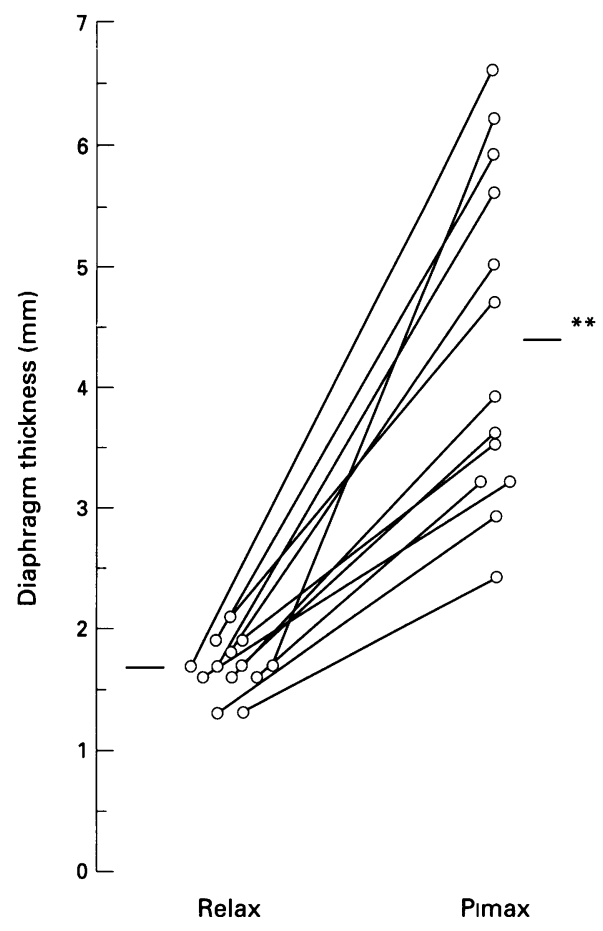

Figure 5 Diaphragm thickness at FRC during relaxation and during the PImax manoeuvre in 13 men. Mean values are indicated by horizontal bars. $* * p<0.01$ compared with thickness during relaxation.

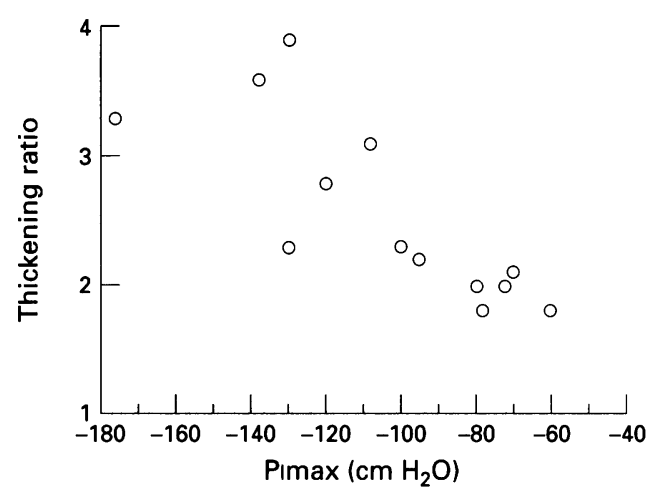

Figure 6 Relationship between thickening ratio (TR) and PImax in 13 men $(r=-0 \cdot 82, p<0 \cdot 01)$.

the PImax manoeuvre was found in all 13 men (fig 5). The mean (SD) PImax was - 104 (33) $\mathrm{cm} \mathrm{H}_{2} \mathrm{O}$ and diaphragm thickness increased from $1.7(0.2) \mathrm{mm}$ during relaxation to 4.4 $(1.4) \mathrm{mm}$ during the PImax manoeuvre (paired $t$ test, $\mathrm{p}<0.01)$. There were significant relationships between thickness during the PImax manoeuvre and PImax $(r=-0.71, \mathrm{p}<0.01)$ and between TR and PImax $(r=-0 \cdot 82$, $\mathrm{p}<0.01$, fig 6 ) in the 13 men, a lower TR being associated with a less negative PImax. There were also correlations between thickness at TLC and PImax $(r=-0.59, \mathrm{p}<0.05)$ and between thickness at TLC and thickness during the PImax manoeuvre at FRC $(r=0.73$, $\mathrm{p}<0.01)$. However, there were no significant correlations between relaxed diaphragm thickness at FRC and PImax or between thickness at RV and PImax.

\section{Discussion}

This study shows that it is possible to visualise the thickness of the diaphragm in the zone of 
apposition during relaxation and to demonstrate its thickening during a maximum inspiratory effort. This may improve the assessment of diaphragm force production in two ways by (1) providing an indication of diaphragm thickness and, indirectly, mass, and (2) by directly indicating diaphragm recruitment during a maximum inspiratory effort.

\section{METHODOLOGICAL CONSIDERATIONS}

It has not been possible to visualise diaphragm contraction clearly in vivo until the introduction of high resolution ultrasound. Initial attempts were made to observe the diaphragm dome through the right upper quadrant of the abdomen using conventional ultrasound. ${ }^{11}$ The diaphragm, however, was shown as a brightly echogenic arc over the liver with poorly defined borders whose thickness reached or exceeded $10 \mathrm{~mm}$ due to the diaphragm-lung interface. The image of the diaphragm did not show the echo-poor appearance typical of muscle. In contrast, the zone of apposition of the diaphragm is easier to observe using high resolution ultrasound. Using high resolution $M$ mode (time-motion) ultrasound an increase of diaphragm thickness in the zone of apposition with an increase of lung volume from FRC was shown by Wait et al. ${ }^{7}$ Although the absolute increase of thickness differed between subjects, large proportionate increases in thickness were measured during breathing. Using high resolution $\mathrm{B}$ mode (two dimensional) ultrasound ${ }^{8}$ the diaphragm image was shown to have five layers; two outer bright parallel layers of the parietal pleura and peritoneum with an irregular bright layer which is due to connective tissue and vessels within the echo-poor diaphragm muscle layer. A B mode picture gives better orientation of the diaphragm during contraction than an $\mathrm{M}$ mode picture and the right hemidiaphragm was easier to observe than the left due to its large contact surface with the liver. The transducer was held firmly against the chest wall. When the angle of incidence changed significantly from perpendicular to the chest wall, the two parallel lines of pleura and peritoneum were either distorted or lost altogether. ${ }^{7}$ The resolution of the $7 \cdot 5 \mathrm{MHz}$ transducer $(0.3 \mathrm{~mm})$ is high enough to observe the diaphragm. A zone of apposition was present in all subjects at TLC, as also recently described using magnetic resonance. ${ }^{12}$ The ultrasonographic measurement is simple, noninvasive, and showed good repeatability. The measurement was difficult in obese subjects and in those in whom there was large movement of the chest wall during the Pimax manoeuvre.

DIAPHRAGM THICKNESS DURING RELAXATION The average thickness at FRC in the present study $(1 \cdot 7(0 \cdot 2) \mathrm{mm})$ was slightly less than the reported mean value of $2.2(0.4) \mathrm{mm}$ in two previous series of 10 seated men ${ }^{7}$ and 31 supine men $^{8}$ which used high resolution ultrasound. A part of this difference may be explained by our measuring between the middle rather than the outer edges of the pleura and peritoneum, whose thickness is exaggerated by ultrasound. Necropsy measurements of diaphragm thickness have given inconsistent results; thus Steele and Heard, ${ }^{13}$ who measured thickness of the muscle directly, reported an average thickness of $2.9 \mathrm{~mm}$ in 15 elderly men without cardiopulmonary disease and $2.3 \mathrm{~mm}$ in seven elderly women. Arora and Rochester ${ }^{14}$ found an average thickness of $3.5 \mathrm{~mm}$ in middle aged subjects without cardiopulmonary disease but derived a mean muscle thickness from measurements of total volume and area of the excised muscular part of the diaphragm. It is not known how such measurements relate to in vivo dimensions; in the quadriceps muscle considerable post-mortem swelling of muscle fibres has been described. ${ }^{4}$

In the quadriceps femoris muscle there is a wide range of maximum voluntary force which, in part, relates to variation in relaxed cross sectional area. ${ }^{56}$ There are probably similar variations in diaphragm mass; for instance, at necropsy diaphragm and body weight are related and at a given body weight the diaphragm weighs more in men than women. ${ }^{15} \mathrm{~A}$ recent abstract using ultrasound ${ }^{16}$ reports that weight lifters with PImax 50\% greater than control subjects had a thicker diaphragm in the zone of apposition, confirming the necroscopic study of Arora and Rochester ${ }^{14}$ who found that a subgroup of six men who had undertaken heavy manual work in life had a heavier and thicker diaphragm than the remaining normal subjects. In the present small study there was a relatively narrow range of relaxed diaphragm thickness and no relation was found with PImax; probably a wider range of muscularity, age, and sex would be required to establish the relation between diaphragm thickness and Pimax. Because PImax indicates the pressure produced in the thoracic cavity, there is a degree of freedom between maximum force developed in the diaphragm and PImax which would be expected to make any relation less tight than that between force and cross sectional area in the quadriceps.

We found a correlation between thickness at TLC and PImax. The greatly increased thickness at TLC was presumably related to the vigorous contraction and shortening needed to maintain full inflation - the thickness being similar to that during a PImax maneouvre at FRC. Because of the shortening of the muscular part of the diaphragm with increase in lung volume, some thickening would be expected when relaxed. We have not studied this systematically but thickness of the relaxed diaphragm at TLC and at 75\% VC (approximately $83 \%$ TLC) averaged $112 \%(n=11)$ and $65 \%$ $(n=9)$ more than at FRC (50-55\% TLC), respectively.

DIAPHRAGM THICKNESS DURING CONTRACTION The measurement of PImax during maximum inspiratory effort at FRC is widely used to assess respiratory muscle strength ${ }^{12}$ and in most normal subjects is associated with maximum 
excitation of the diaphragm. ${ }^{17}$ Using high resolution ultrasound, diaphragm thickness in the zone of apposition increased significantly during the PImax manoeuvre and the thickening ratio of the diaphragm was strongly correlated with the value of PImax (fig 6). We were surprised at the extent of diaphragm thickening during the PImax manoeuvre, the thickening ratio ranging from 2.0 to $3 \cdot 9$. This increase in thickness during contraction is disproportionate to the likely thickening due to shortening. Another unexpected finding was the considerable thickening found with minor contraction (fig 4). Even during relaxation against a closed airway at TLC the thickness of the diaphragm averaged more than twice the relaxed thickness at FRC, whereas it has been estimated that overall diaphragm muscle length at TLC is $55-87 \%$ of resting length at FRC. ${ }^{18}$ Similar thickening of the diaphragm in the zone of apposition associated with muscle contraction or increase in lung volume has been described in two previous ultrasound studies. ${ }^{78}$ The resolution of the ultrasound image remains good during the manoeuvre (fig 3 ). An obvious explanation for these results is that there are regional differences in shortening in the diaphragm; considerable regional differences have been described in $\operatorname{dogs}{ }^{19}$ but not in a systematic way in the zone of apposition. Regional differences in canine diaphragm thickness after excision have also been described. ${ }^{20}$ Another possibility is that vascular changes could be important during muscle contraction because the vessels run between the muscle fibres. Clearly, further studies are required to establish the origin of the observed increase in thickness.

In conclusion, ultrasound provides a simple method of directly assessing thickness and contraction of the diaphragm in the zone of apposition. The technique is non-invasive and repeatable in the same subject. The thickening ratio at FRC may be a good indicator of diaphragm strength. The investigation usually takes about 15 minutes and can be applied at the bedside and, potentially, in the intensive care unit.

We are grateful to Ann Watson for her assistance in performing studies and Toshiba Medical System Co Ltd for support. J Ueki was a recipient of a Glaxo International Charitable Trust Fund was a recipient of a Glaxo International Charitable Trust Fund Scholarship. Dr Pedro FC De Bruin was supported by Conselho
Nacional de Desenvolvimento Cientifico e Tecnologico-CNPq of Brazil.

1 Black LF, Hyatt RE. Maximal respiratory pressure: normal values and relationship to age and sex. Am Rev Respir Dis 1969;99:696-702.

2 Green M. Respiratory muscle testing. Bull Eur Physiopathol Respir 1984;20:433-6.

3 Ringqvist T. The ventilatory capacity in healthy subjects. Scand f Clin Lab Invest 1966;18(Suppl 88):1-179.

4 Alexander R Mc N, Vernon A. The dimensions of knee and ankle muscles and the forces they exert. $f$ Hum Morphol Stud 1975;1:115-23.

5 Maughan RJ, Watson JS, Weir J. Strength and cross-sectional area of human skeletal muscle. $\mathcal{F}$ Physiol (Lond) 1983;338: $37-49$.

6 Young A, Stokes M, Crowe M. Size and strength of the quadriceps muscles of old and young women. Eur $7 \mathrm{Clin}$ Invest 1984;14:282-7.

7 Wait JL, Nahormek PA, Yost WT, Rochester DF. Diaphragmatic thickness-lung volume relationship in vivo. $\mathcal{f}$ Appl Physiol 1989;67:1560-8.

8 Taniguchi N, Miyakoda J, Itoh $\mathrm{K}$, Fukui J, Nakamura M, Suzuki O. Ultrasonic images of the diaphragm and $M$, Suzuki O. Ultrasonic images of the diaphragm and respiratory changes on

9 Quanjer PH. ed. Standardized lung function testing. Bull Eur Physiopathol Respir 1983;19(Suppl 5):1-95.

10 Altman DG, ed. Practical statistics for medical research. London: Chapman and Hall, 1991.

11 Fried AM, Cosgrove DO, Nassiri, McCready VR. The diaphragmatic echo complex: an in vitro study. Invest Radiol 1985;20:62-7.

12 Gauthier AP, Verbanck S, Estenne M, Segebarth C, Macklem PT, Paiva $\mathbf{M}$. Three dimensional reconstruction of the in vivo diaphragm shape at different lung volumes. of the in vivo diaphragm shape at
$\mp$ Appl Physiol 1994;76:495-506.

13 Steele RH, Heard BE. Size of the diaphragm in chronic bronchitis. Thorax 1973;28:55-60.

14 Arora NS, Rochester DF. Effect of body weight and muscularity on human diaphragm muscle mass, thickness, and area. F Appl Physiol 1982;52:64-70.

15 Thurlbeck WM. Diaphragm and body weight in emphysema. Thorax 1978;33:483-7.

16 Conomos P, Curtin L, McCool F. Inspiratory strength and diaphragm thickness in weight lifters. Am $\mathcal{f}$ Respir Crit Care Med 1995;151:A807.

17 Bellemare F, Bigland-Ritchie B. Assessment of human diaphragm strength and activation using phrenic nerve stimuphragm strength and activation using phr

18 Loring SH, Mead J, Griscom NT. Dependence of diaphragmatic length on lung volume and thoracoabdominal configuration. $\mathcal{F}$ Appl Physiol 1985;59:1961-70.

19 Sprung J, Deschamps C, Hubmayr RD, Walters BJ, Rodarte $\mathrm{JR}$. In vivo regional diaphragm function in dogs. $\mathcal{F} A p p l$ Physiol 1989;67:655-62.

20 Margulies SS. Regional variation in canine diaphragm thickness. F Appl Physiol 1991;70:2663-8. 